\title{
Doctors alleging sexist behaviour at top of BMA criticise its formal conduct procedures
}

\author{
Melanie Newman \\ London, UK
}

The doctors behind accusations of sexism and inappropriate behaviour among senior members of the BMA have reported their lack of faith in the organisation's own conduct processes. In an article for GPOnline ${ }^{1}$ on 1 April, Zoe Norris and Katie Bramall-Stainer from the BMA's General Practitioners Committee (GPC) described a misogynistic and outdated culture at the top of the organisation, which they said had forced women out of medical politics. Norris has decided to step down from the GPC in protest.

Chaand Nagpaul, chair of BMA Council, said that the BMA was committed to an external investigation, independent of the association, to look into this matter.

But Norris and Bramall-Stainer told The BMJ that they had no confidence in any inquiry led by the BMA and that only a "wholly independent" investigation would do. To be truly independent the investigation would have to be run by someone with no ties to the organisation, they said.

Norris said, "My faith in the BMA and its leadership is so broken that unless the inquiry is conducted by someone with no association with it or its senior officers-historical or otherwise - I believe it will not be done properly. The investigation has to be wholly independent."

On 20 March, Bramall-Stainer wrote on Twitter that, before walking onto the stage as co-chair at the annual conference of local medical committees in Belfast, she had been called a "naughty girl" and a "little girl" by a "very senior member of conference."

GPC member Stephanie deGiorgio also tweeted that she had been called a "naughty girl" by "someone very senior" after challenging England's former health secretary, Jeremy Hunt, at a conference, and Norris said she had been addressed in a similar way.

Hundreds of colleagues subsequently contacted the doctors to report hearing jokes about women's bra sizes, receiving unsolicited sexual propositions, naked pictures, and "patting of bottoms" by fellow committee members. Norris and Bramall's subsequent article detailing these incidents prompted Nagpaul, who led the GPC until he became chair of council in 2017, to announce an investigation into the allegations.

Nagpaul said, "I am appalled to hear of the treatment my colleagues describe and of similarly unacceptable behaviours. I'm sorry and I offer my heartfelt apologies on behalf of the whole association." He added: "We will be reviewing and identifying additional ways in which members can safely and effectively raise concerns. These processes must be there to ensure that members feel supported."

GPC chair Richard Vautrey said he was "seriously concerned and saddened" to hear accounts of unacceptable behaviour by male GPC members.

Given both doctors' longstanding roles as senior GP members of the BMA, questions are inevitable about their knowledge of the culture described and their lack of prior action. At the time of going to press, neither Vautrey nor the BMA press office had responded to The BMJ's query about when the GPC chair had learnt of the comments described in the women's tweets.

GP Tom Caldwell tweeted in response to Vautrey's comments: "The investigation would be considerably easier if those who know they have done this simply had the decency to admit it and resign. This should not be too much to expect."

The BMA's formal conduct procedure, known as Living Our Values (LOV), has a poor reputation within the organisation.

Norris told The BMJ she had previously raised a complaint about inappropriate behaviour with senior GPC and BMA officers, as well as through the LOV process. She said she had found the process more traumatic than the behaviour that formed the subject of her complaint. "LOV seems to operate differently depending on who is bringing a complaint and who the complaint is about," she added.

DeGiorgio echoed her concerns, adding, "I have no faith in the BMA's own investigatory and conduct processes, having experienced them previously. The inquiry needs to be done by someone with absolutely no previous connection to the BMA or its officers. The BMA has to understand it cannot just pay lip service to this. We are not going to go away."

Scottish GPC member Amy Small said she had stepped down from the UK-wide committee after being bullied by one of its senior male members. She made a complaint but nothing changed, she said. When the same person undermined her at a conference by commenting on her appearance she did not go through LOV but brought the remark up with the Scottish BMA Council chair who resolved the matter informally. "I knew what Zoe had been through with the LOV process, plus the process seemed very removed from Scotland," she said.

A BMA spokesperson said, "Neither Dr deGiorgio nor Dr Small has ever raised a complaint, formal or informal, under the LOV process. Dr Norris has never made a complaint under the process about the allegations referred to elsewhere in the article." 
"The statement 'The BMA's formal conduct procedure, known as Living Our Values (LOV), has a poor reputation within the organisation' cannot, in our view, be supported. It would be unethical and a breach of trust and confidentiality for the BMA to list details of those members who have been successfully supported by our formal conduct procedures. The feedback we have received from many members demonstrates that LOV has been a positive step in creating a culture that is inclusive of all members.

"The BMA is clear that these processes must be there to ensure that members feel supported, and we want to make sure they are absolutely fit for purpose. We want every member to feel able to contribute, knowing that their points of view will be valued and differences of opinion will be respected."
Meanwhile former GPC member and GP negotiator Beth McCarron-Nash defended her male colleagues, saying she had never experienced any sexism or inappropriate treatment by male members of the committee. "The BMA has been brilliant to me," she said. "It paid for a nanny for my son and if it had not done that I would never have risen as I high as I did within the organisation."

Correction: On Friday 5 April we added the BMA spokesperson's response.

1 Bostock N. Sexism at the BMA has cost general practice a generation of leaders. GP Online. Apr 2019. www.gponline.com/sexism-bma-cost-general-practice-generationleaders/article/1580508.

Published by the BMJ Publishing Group Limited. For permission to use (where not already granted under a licence) please go to http://group.bmj.com/group/rights-licensing/ permissions 